\title{
Physics for Surgeons - Part 4: Energy Devices in Surgery
}

\author{
Darakhshan Qaiser", Piyush Ranjan, Kamal Kataria, Anita Dhar, Anurag Srivastava \\ Department of Surgery, All India Institute of Medical Sciences, New Delhi, INDIA
}

* Corresponding author email: qaiser.d@gmail.com

Received: 23 July 2019 / Revised: 31 October 2019 / Accepted: 08 April 2020 / Published: 13 April 2020

\begin{abstract}
Modern surgery has advanced astoundingly in the last century owing to the advent of number of energy devices in the operation room. Surgeon in the past were only using electric current -monopolar diathermy to burn and couterize the tissue, the present day surgeons are equiped with a number of more advanced energy devices e.g. LASER, ultrasonic vibrating shears, radiofrequency, shockwaves, argon beam coagulator and advanced bipolar electric energy with hybrid systems and light energy of different wavelengths. In the present paper, we have explained the physical principles involved in the commonly used energy devices in the operation theatre.
\end{abstract}

Keywords: Energy Devices, Laser, Electrical Devices, Ultrasonic., Light

\section{Introduction}

Many principles of Physics find numerous applications in the field of medicine and surgery. These principles are not new but having a conscious effort to see its application in routine surgery practice is rare. The understanding of these principles and their application in the routine surgery would transform a surgeon to think more like a scientist. An effort has therefore been made to highlight the principle of physics and their application in surgery through a series of articles[1]-[3].In the first part of this series we described some applications of the laws of hydrodynamics governing the flow of blood and other body fluids. Principles of physics in surgery-Part 1 [1] includes some prominent applications of the laws of fluid mechanics and hydrodynamics in surgery. Laws of Mechanics, Thermodynamics and Vectors as they apply to soft and bony tissues was discussed in the next sequel Principles of Physics in Surgery - Part 2[2]. Second part of this series include Pascal's Law that finds use in hernia repair and the Heimlich maneuver. Laplace's Law as applied to colonic perforation, compression therapy, parturition, variceal rupture, disc herniations etc. was also discussed in the second part of this series. Third part of the series, Physics for Surgeons Part3: Why Cyst Is Spherical in Shape [3], describes Physical characteristics of a swelling (cyst) by using principles of fluid mechanics. This article is another effort in this sequel to highlight the application of basic physics by considering energy devices in surgery.

\section{Energy Devices in Surgery}

Bleeding is considered to be the nightmare for any surgeon. To help surgeon in controlling bleeding these energy sources play a vital role. During surgery, surgeons require energy source which can dissect the tissue and at the same time can achieve hemostasis[4]. With time there are remarkable advancement in energy sources to improve the speed of surgery with minimal collateral damage. Energy Sources in surgery are:
2.1. Electrical
2.2. Ultrasonic
2.3. LASER
2.4. Argon Beam Coagulator 

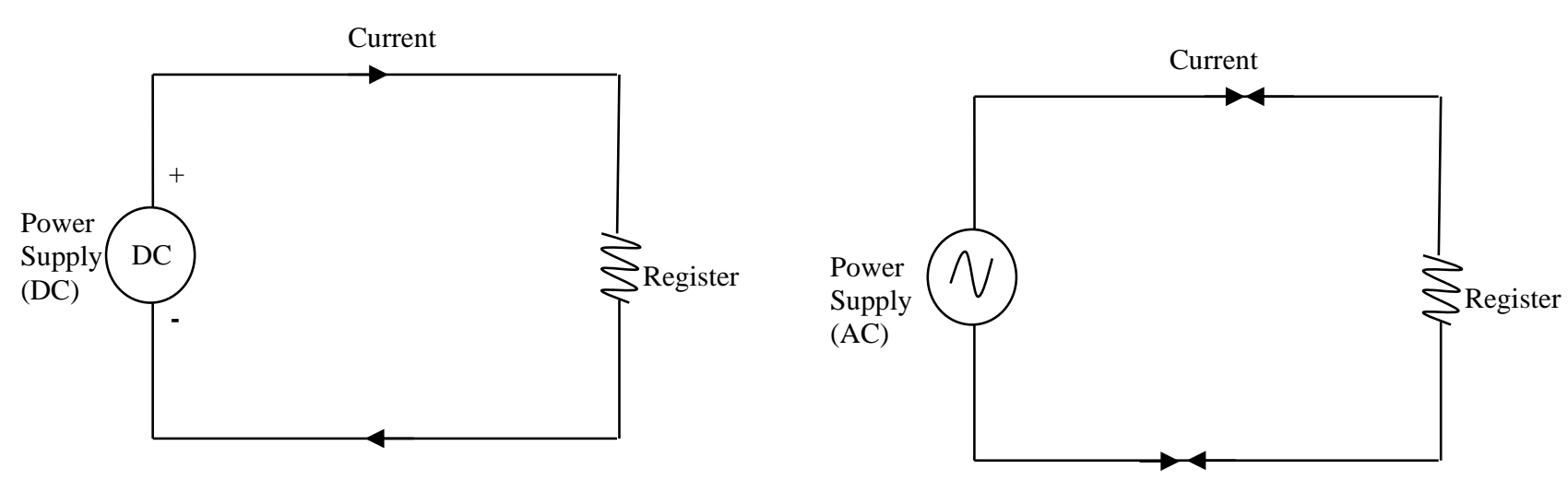

Figure 1: Circuit diagram showing flow of current in DC and AC mode

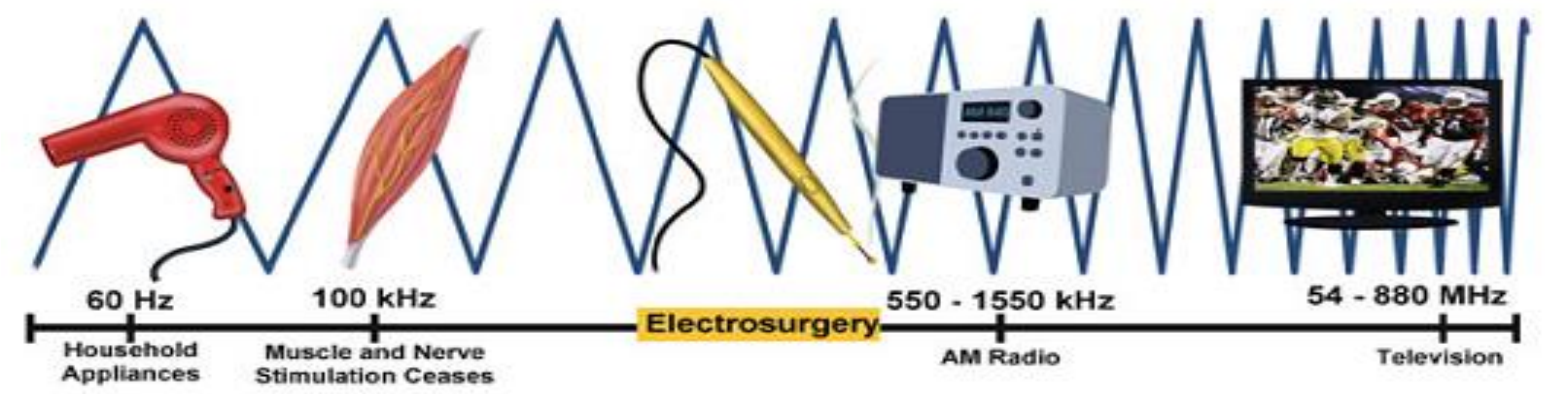

Figure 2: Frequency spectrum for electrosurgery.

\subsection{Electrical Energy Devices}

Electrical energy for surgical procedures has been used from late of nineteenth century[5]. Electrosurgery uses the radio frequency (RF) with alternating Current (AC) which raise intercellular temperature to achieve vaporization, dissection, cutting or coagulation of tissue. Concept of electrosurgery is different from process of electrocautery. In electrocautery, direct current (DC) is used (i.e; electrons move in one direction only) and current does not enter in the patient's body. Patient's body is not the part of circuit; therefore, only heated wire comes in contact with tissue. Whereas, in electrosurgery alternating current is used for raising the temperature of tissue and patient's body is also a part of electric circuit. For any electrical circuit, there must be two poles positive and negative to create the movement of ions. In DC circuit, polarity of electrodes is constant. While the polarity of electrodes changes with time, in alternating current (shown in Figure 1). Frequency at which the electro-surgical instrument work is shown in Figure 2., Since, nerve and muscle stimulation ceases at frequency $\leq 100 \mathrm{KHz}$, electrosurgery can be perform safely at above $100 \mathrm{KHZ}$.

\subsubsection{History of Electrosurgery}

The use of heat energy for bleeding control has been mentioned even in the Shushrut Samhita. Ancient Egyptians (300BC) used thermal cautery for treatment of ulcer and breast tumor. Hippocrates used heat to destroy neck tumor [6]. However, in the eighteenth century, Benjamin franklin and John Wesely was the first who described the use of direct current (DC) for medical therapeutics[7]. Bovie (physicist) and Cushing (Neurosurgeon) hasbeen credited for the invention of electrosurgery[5]. (see Figure 3). In 1941, Power and Barnes were the first to report the human performance of laparoscopic electrosurgical female sterilization using Monopolar cautery [8]. With time, further development and popularization of laparoscopic surgery leads to bipolar instrument used by Frangenheim and Rioux [9], [10].

Now, Radiofrequency electrosurgery has been widely accepted and highly effective technique for cutting and hemostasis. Bipolar instrument gives safety advantages over unipolar when used 
for the process of coagulation and desiccation but not useful in cutting and vaporization. Safe and effective use of instrument requires sound understanding of electrosurgical principles.
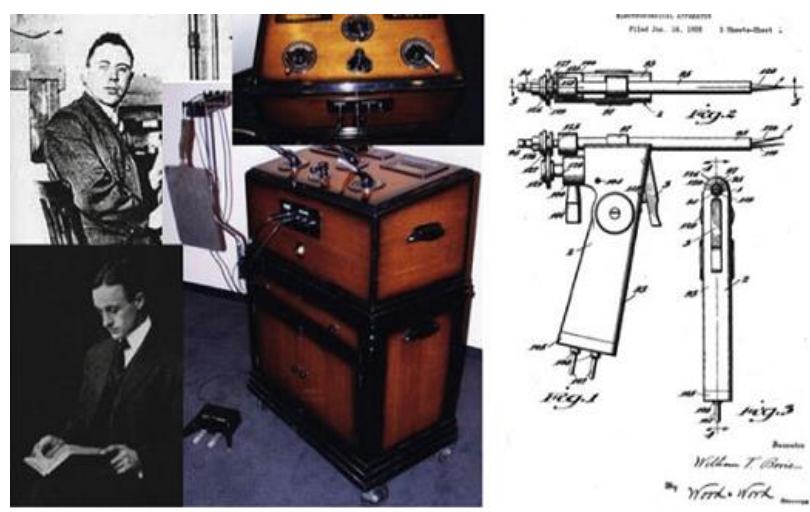

Figure 3: W.T. Bovie (upper left) was the inventor of electrosurgical generator, H.W. Cushing (lower Left) was the first to use the instrument in 1926.

\subsubsection{Basic Principles of Electrosurgery}

In electrosurgery, an alternating current (AC) is used in the tissue to create thermal effect through ohmic heating which is selectively used to destroy the tissue. In electrosurgery, tissue behaves as $\mathrm{s}$ ohmic resistor. Alternating current has frequency atleast $300 \mathrm{KHz}$ is used to avoid unwanted electrolysis in the tissue (since stimulation of nerve occurs at lower frequency). Therefore, electrosurgery is also callled as high frequency (HF) surgery or radiofrequency (RF) surgery. In the process of RF electrosurgery, Inside the cells, electromagnetic energy first converting to kinetic energy and then in to Heat energy. Desired effect of electrosurgery depends on the electrical properties and tissue exposure time, area, size and surface area of electrode in contact with tissue.

Joule effect is the basic principle behind the heating of tissue in the electrosurgery Current is applied between the electrodes namely active and neutral respectively. There are three electrical properties which effects the temperature rise in tissue i.e.; current (I), voltage $(\mathrm{V})$, and impedance or resistance (R). In an electronic circuit these properties are in relation known as Ohm's law describe by George Ohm in 1827 [11] and is known as Ohm's law:

V (Voltage) $=\mathrm{I}$ (Current) X R (Resistance),

$$
\text { or } I=V / R
$$

Another important electrical property which defines the relation between current and voltage is Power $(\mathrm{P})$ :

$$
\begin{aligned}
\text { Power }(\mathrm{P})= & \text { voltage }(\mathrm{V}) \mathrm{X} \text { Current }(\mathrm{I}) \\
& \text { or } \mathrm{P}=\mathrm{V}^{2} / \mathrm{R}
\end{aligned}
$$

Power density is proportional to the square of the current. When the electrode is in punctural contact with tissue, strongest heating occurs. The power density then decreases with fourth power of distance as the current penetrate deeper in the tissue. Active electrode is the point where thermal effect occurs, which has small contact area (figure 4). For Monopolar system, the neutral electrode is like a plate which has larger area. Therefore, low current density is generated for thermal effect. For bipolar system, both electrodes are integrated in the same instrument.

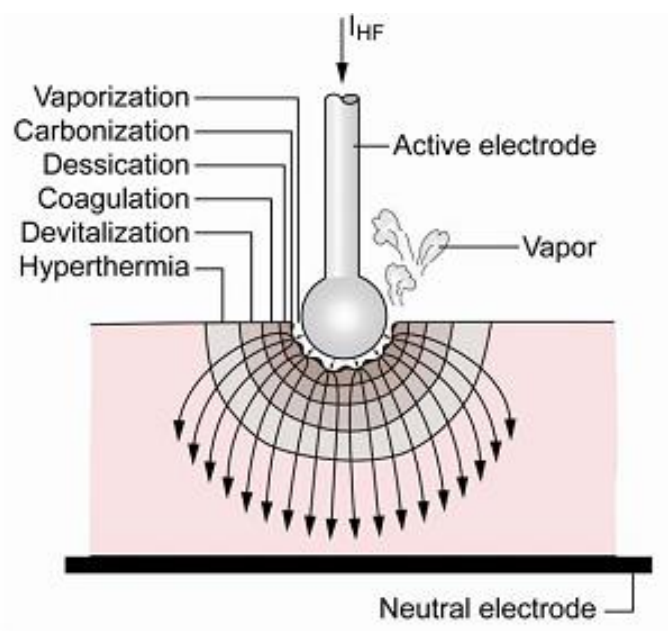

Figure 4: Schematic diagram showing thermal effect at active electrode [12]

Thermal effect mainly depends on the rate of heating and attained temperature $(\mathrm{T})$ which in turns depends on power density and exposure time. In tissue, Thermal effect classified into two categories: coagulation (slower heating $\mathrm{T}<100$ ${ }^{\circ} \mathrm{C}$ ) and cut (quicker heating $\mathrm{T}>100^{\circ} \mathrm{C}$ ) [12].

Thermal Effects in Human Tissue: In general, there is no irreversible cellular damage in human tissue below $40^{\circ} \mathrm{C}$. Phenomenon of Hyperthermia occurs when temperature raises from $40^{\circ} \mathrm{C}$ to $50^{\circ} \mathrm{C}$. In this temperature range, changes appear in cellular membrane and interstitial fluid increases due to water secretion by cells (oedema formation). These changes are reversible depending upon the duration of 
heating, but after several minutes tissue may burn. Denaturation of internal protein called coagulation occurs from temperature $60^{\circ} \mathrm{C}$ to $80^{\circ} \mathrm{C}$ and leads to cell death (necrosis). When intercellular protein coagulates and then transform into gelatin. Cellular liquid evaporates at temperature $100^{\circ} \mathrm{C}$. Additional heat is converted in to energy of evaporation. Vapour pressure leads to mechanical destruction of tissue. Table 1indicates the overview of temperature on human tissue.

Table 1: Thermal effect on human tissue

\begin{tabular}{|l|l|}
\hline $\begin{array}{l}\text { Tissue } \\
\text { temperature }\end{array}$ & Effect \\
\hline$<40^{\circ} \mathrm{C}$ & None \\
\hline $40-50^{\circ} \mathrm{C}$ & $\begin{array}{l}\text { Hyperthermia: Changes appears } \\
\text { in cellular membrane and } \\
\text { internal molecular structure, } \\
\text { oedema formation time } \\
\text { dependent cell death (necrosis) }\end{array}$ \\
\hline 60 to $80^{\circ} \mathrm{C}$ & $\begin{array}{l}\text { Coagulation (Denaturation of } \\
\text { internal proteins), Destruction } \\
\text { of cell membranes and } \\
\text { coagulation of extracellular } \\
\text { collegen, Devitalization }\end{array}$ \\
\hline $100^{\circ} \mathrm{C}$ & $\begin{array}{l}\text { Evaporation of cell liquid / } \\
\text { vaporization (depending on } \\
\text { heating power) }\end{array}$ \\
\hline Above $100^{\circ} \mathrm{C}$ & \begin{tabular}{l} 
Carbonization \\
\hline
\end{tabular} \\
\hline
\end{tabular}

Conductivity of tissue also plays an important role in heat generation. Figure 5 indicates behavior of conductivity as a function of temperature. As the temperature of tissue increases conductivity of tissue also increases in a reversible way due to dissociation of electrolyte in cellular liquid. Above $60^{\circ} \mathrm{C}$, tissue get coagulated causing additional and irreversible increase in the conductivity due to disruption of cell membrane. At $100^{\circ} \mathrm{C}$, fall in conductivity due tissue desiccation [12].

\subsubsection{Types of electrosurgical Systems}

There are two types of electrosurgical systems

- Monopolar or unipolar

- Bipolar

- Ligasure vessel sealing system (LVSS)(R)

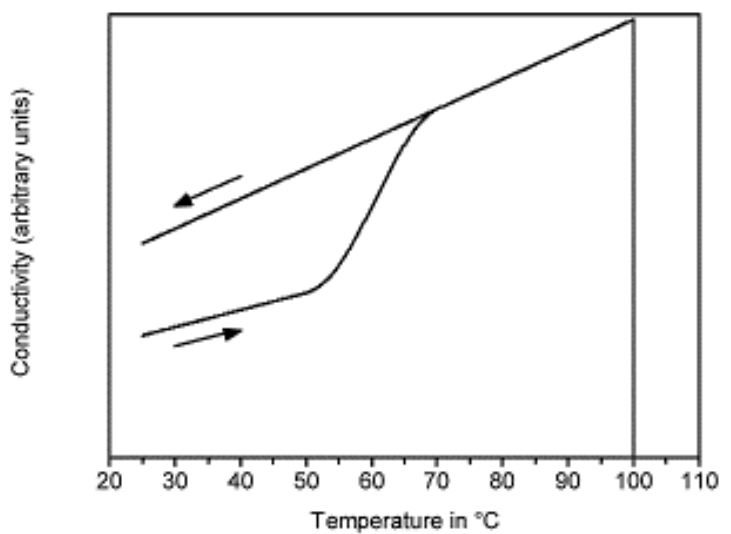

Figure 5: Schematic diagram showing Conductivity of tissue with temperature [12]

\subsubsection{Monopolar Instrument}

Monopolar Instrument have two separate electrodes in the circuit, one servesas active electrode and another as dispersive or passive electrode and the lateral interposed between the two electrodes (as shown in the figure 6).

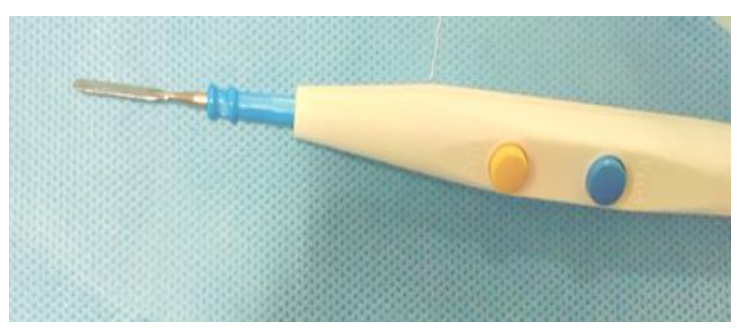

Figure 6: Monopolar Electrode with bladed metalic tip and a yellowbutton for cutting and blue button for coagulation

For the purpose of cutting or vaporizing, the active electrode should be made like point hook, narrow tip, or bladed edge. For local coagulation, desiccation of hemostasis, active electrode should be of slightly large surface area like side of a blade or is in the form of grasper. Figure 7 (a) and (b) indicates the bladed and hook edge of active electrode for Monopolar system. The better name for active electrode can be "power or current concentrating electrode".

(a)

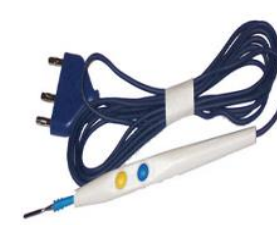

Figure 7: Electrodes for Monopolar system. Active electrodes showing bladed (a), hook (b) edge, and (c) Passive Electrode 
Dispersive electrode is positioned on the patient's body relatively with large surface area (figure $7 \mathrm{c}$ ) and serves to disperse the current thereby preventing tissue injury. It always designed with an adhesive for proper contact with patient. The Current and power density increases if dispersive electrode partially detached from the patient's body. This in turn makes the dispersive electrode active and can cause thermal injury. Monopolar have some advantages like, it is easy in use, can be used for cutting, coagulation and desiccation process.

Limitations: Requirement of dispersive or passive electrode. More collateral damage to the larger thermal damage because the current passes through the body tissue between the active and passive electrodes. This passage of current through the body may cause thrombosis of blood in blood vessels and may cause rhythm disturbance in the conductive tissue of heart. Hence, its use in contraindicated in fingers, toes and genetilia.

\subsubsection{Bipolar Instrument}

In bipolar instrument both electrodes are positioned on the same instrument (Figure 8). The fundamental concept behind the bipolar system is that only part of patient tissue will involve in the circuit. Tissue is imposed between the electrodes.

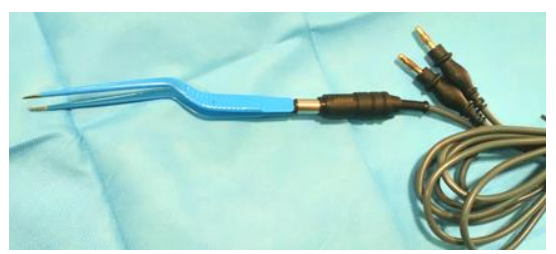

Figure 8: Bipolar instrument

The hand instrument consists of a "non-toothed dissecting forceps" with two points acting as two electrodes are insulated from each other. These electrodes are made of flat surface to provide ease to surgeon for grasping and compressing the tissue. The current passes through the tissue grasped between the two electrodes. Thus, there is very little "collateral thermal or electrical damage around the tissue being cauterized. Keeping in mind the Ohm's law, we should grasp very little tissue so that enough current passes generating sufficient heat to coagulate the blood vessels and stop bleeding. Please note that the bipolar cautery is primarily used for dissecting and haemostasis where there is vital tissue in vicinity, viz. nerves, parathyroid glands, near an implant and of course the brain.

Advantages: Small volume of tissue is heated and coagulated with minimal collateral damage. No risk of inducing arrhythmia, so, it is safe to use in patients with heart disease and in patients with a pacemaker.

\subsubsection{Ligasure vessel sealing system $\left(\right.$ LVSS) ${ }^{(\mathbf{R})}$}

It is an advanced bipolar instrument (shown in Figure 9) used for sealing vessels up to $7 \mathrm{~mm}$ in diameter. It seals tissue by application of high current with low voltage $(180 \mathrm{~V})$. The phenomenon of sealing occurs due to unique combination of pressure energy with electric current. It applies high coaptive pressure during generation of temperature in the tissue, at this stage hydrogen cross link are first ruptured and then renature with the results of sealing with high tensile strength. Melted collagen and elastin provide plastic like permanent sealing up to $7 \mathrm{~mm}$ in diameter. Average seal cycle is $2-4 \mathrm{sec}$. LVSS has a unique property of active tissue response i.e; feedback on the electric bioimpedance from coagulates tissue. This property controls the energy delivery and automatically shut it when tissue seal cycle completes and tissue does not stick with jaw of LVSS [13], [14]. Operation time of LVSS is less than the operation time of ultrasonic device [15]-[17]. The heat generated is minimal (average temperature $=50-60$ degree centigrade, hence, collateral tissue damage is minimal. Another advantage of the Ligasure device is the rubber insulation around the tip of the electrodes making them safe for dissection around a fragile vessel and also limiting the heat transmission to surrounding tissue.

Limitation: There is carbon deposit on the blades which needs frequent cleaning for proper functioning.
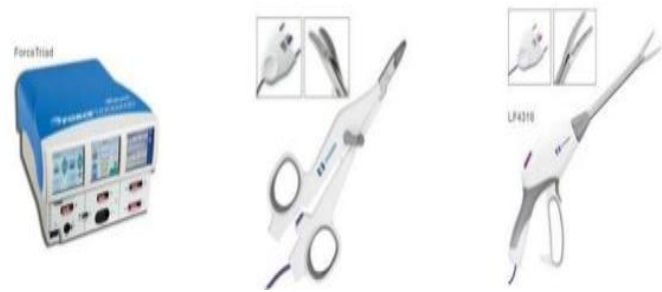

Figure 9: Ligasure vessel sealing system 
D. Qaiser et al., Int. Ann. Sci.; Vol. 9, Issue 1, pp:122-131, 2020

\subsection{Ultrasonic Energy Devices}

\subsubsection{Harmonic Scalpel $(\mathbf{H S})^{(\mathrm{R})}$}

Harmonic Scalpel is a surgical instrument which simultaneously cut and coagulates tissue. It uses ultrasonic vibration to cut the tissue instead of electric current. Harmonic scalpel is works at frequency $55.5 \mathrm{KHz}$ or 55,500 vibrations / sec. The vibration of cell content at this high speed, evaporates the cytoplasm. This in turn breaks the intercellular bridges and allows tissue dissection. Therefore, it is also known as ultracision. It also causes coagulation of blood vessels wall and seals the vessels up to 5-7 $\mathrm{mm}$ in diameter, whereas, hook and blade can achieve coagulation of only up to $2 \mathrm{~mm}$ in diameter [4]. The instrumental arrangement consists of ultrasound (US) transducer placed in hand piece which is composed of piezoelectric crystal sandwiched under pressure among metal cylinders [18]. In harmonic scalpel, ultrasonic energy is converted in to mechanical energy by ultrasonic generators. The denatured protein coagulum results in sealing of vessels due to tamponade and cooptation of vessel walls. HS comes in three compatible probes i.e; shear, blade and hook (Figure 10) The shear has silicon padding on one blade which is not exists in blade and hook. whereas, hook and blade can achieve only up to $2 \mathrm{~mm}$ in diameter [4].

Advantages: It has minimal thermal spread, no smoke or charring of tissue, no risk of electric shock or arrythmia in patients with cardiac disease and pacemaker.

Limitations: The instrument also gets heated up very quickly. it is unable to coagulate vessels greater than $5 \mathrm{~mm}$ in diameter, dependence of blade setting and cost.

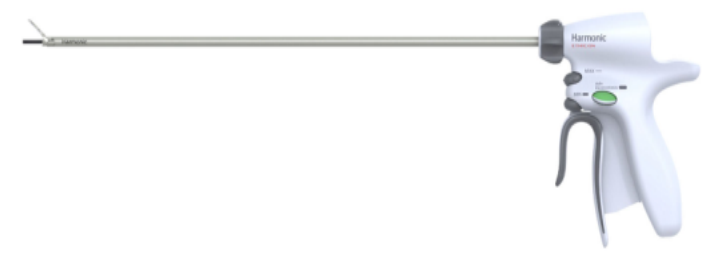

Figure 10: Blade jaw of Harmonic scalpel

\subsubsection{Thunderbeat}

Thunderbeat is the only surgical energy device which combines two types of energy in a single instrument. It is the integration of advanced bipolar energy and ultrasound energy. It provides ultrasonically generated frictional energy simultaneously with electronically generated bipolar energy. It can be used for cutting, dissection, histological sealing, and tissue manipulation. Thunderbeat provides fast cutting with immediate sealing of vessels up to $7 \mathrm{~mm}$ and minimal thermal spread around tissue [18,19].

\subsection{LASER}

In modern medicine lasers are used in treatment of variety of diseases (lithotripsy, treatment of various cancers, ablation of tumors) due to it is less invasive. LASER is the acronym for "Light Amplification by Stimulated Emission of Radiation". The first laser was discovered by Theodore Maiman in 1960 with a crystal of ruby laser which is excited by flash lamp and mirrors to amplify the lasing action [20]. Ruby laser is the first laser used for the surgery in the united states for the treatment of retinal hemorrhages in ophthalmology. In the mid of 1960 s carbon di oxide laser and argon ion laser were developed and used as a surgical tool.

\subsubsection{Laser Physics}

A laser is consisting of resonator (which contains active material for lasing action). This resonator is placed between two parallel mirrors, one is fully reflecting and other is partially reflecting and partially transmitting. Active material is excited by an excitation source (flash lamp, electric current, or another laser) until number of atoms in the excited sate is greater than the number of atoms in ground state (phenomenon is known as population inversion) reached. When lasing material get excited, then it releases photons spontaneously in all directions. Though, a small subset of these photons travels along the centerline of the laser system. Laser light is forth back inside the mirrors when sufficient laser light inside the cavity achieved, a shutter will open to release the light in the form of laser beam. Figure 11 shows the lasing action inside the resonator. 
Properties of lasers: Lasers have following three properties:

- Monochromatic: laser light comprises of single colour due to extremely narrow range of wavelength of light

- Coherence: light waves are highly ordered and correlated in time which results additive effect on amplitude and power. Due to coherence effect laser light is concentrated in small spot size. This results in extremely high-power density in small area to cause tissue damage.

- Directionality: laser light is collimated in in a narrow beam with all waves propagates in parallel and without significant divergence [22].

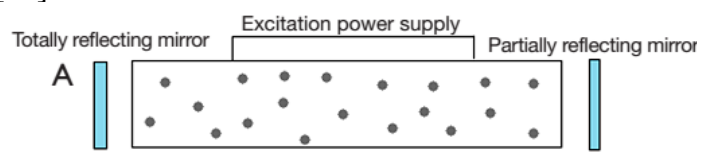

B

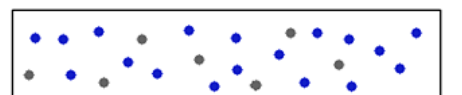

C

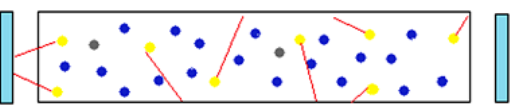

D

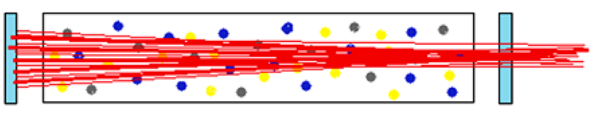

Figure 11: Mechanism of laser action in the cavity,

(A) Atoms at ground state,

(B) excitation of atoms to higher energy levels,

(C) Photons generated by stimulate demission,

(D) Emission of laser Beam [21]

\subsubsection{Types of Laser}

- Pulsed Laser: Produce light in the form of pulse. When light comes in the form of short duration. Such Lasers are called Pulsed Laser.

- Continuous Laser: They are capable of producing continuous beams.

Radiance: It is the power density. It is the amount of power per unit surface area during a single pulse or exposure.

There is various type of laser depending upon the active material used for lasing action like solid state laser, gas laser, liquid laser. Surgeons select appropriate laser to excise or coagulate the tissue.

\subsubsection{Argon Ion Laser}

It's a solid-state laser. This laser emits blue green light with wavelength of $488 \mathrm{~nm}$ and $544 \mathrm{~nm}$. This light passes through water and clear fluid. Its thermal radiation penetration depth is up to 1 or $2 \mathrm{~mm}$ in most tissue. It is mainly absorbed by brown red pigment of chromogenhaemoglobin in blood and converts it into heat.

\section{Uses of Argon Ion Laser}

a) argon laser used to coagulate bleeding point

b) Primarily it uses to remove cutaneous lesion while spearing adjacent tissue. Coagulate superficial vessels in mucosa as in gastrointestinal tract.

c) Also uses in ophthalmology, gynecology, urology, neurosurgery and dermatology.

\subsubsection{Carbon dioxide Laser $\left(\mathrm{CO}_{2} \mathrm{LASER}\right)$}

$\mathrm{CO}_{2}$ laser is a molecular gas laser. It uses mixture of nitrogen $\left(\mathrm{N}_{2}\right)$, carbon di oxide $\left(\mathrm{CO}_{2}\right)$ and helium gas. It emits light from mid infrared to far infrared region of electromagnetic spectrum (9600 $\mathrm{nm}$ and $10,600 \mathrm{~nm})$. This wavelength mainly absorbed by water and increases the water temperature of cells. Thus, uses to vaporize the tissue. Vaporization is the conversion of solid tissue in to smoke or gas. It penetrates from $0.1 \mathrm{~mm}$ to $0.2 \mathrm{~mm}$ with minimal thermal effect to surrounding tissue. A portable hand-held laser tube with hollow needle deliver laser light in the vascular and microsurgery.

\section{Uses of $\mathrm{CO}_{2}$ Laser}

a) Vaporizing and haemostatic action of $\mathrm{CO}_{2}$ laser used for treating soft tissue and vascular lesion.

b) Uses to remove large or small masses of tissue efficiently and rapidly.

c) $\mathrm{CO}_{2}$ laser used in various fields like in gynecology, Plastic surgery, Dermatology, neurosurgery, and in general surgery.

\subsubsection{Krypton Laser}

This laser comes in the category of gas Laser. Krypton Ion gas laser emits a red yellow light with wavelength of 476.2 to $647.1 \mathrm{~nm}$ or $0.6 \mu \mathrm{m}$. This light is intensely absorbed by pigment in 
D. Qaiser et al., Int. Ann. Sci.; Vol. 9, Issue 1, pp:122-131, 2020

blood and retinal epithelium. Krypton ion laser resembles with argon ion laser in its construction and uses.

Uses of Krypton Laser: It is mainly used in ophthalmology. Since, it is poorly absorbed by red of haemoglobin. Therefore, can be effectively used for the treatment of retinal bleeding.

\subsubsection{Neodymium (Nd)-YAG Laser}

It comes in the category of solid-state laser. $\mathrm{Nd}: Y A G$ is the acronym for neodymium, yettrium, aluminium and garnet that comprise solid state crystal. The active medium is a crystal rode of yttrium aluminium garnet (YAG) with impurity of Neodymium (Nd). This laser operates from near infer red to far infra-red region of electromagnetic spectrum. The fundamental wavelength is $1064 \mathrm{~nm}$. This wavelength penetrates from $3 \mathrm{~mm}$ to $5 \mathrm{~mm}$. Light from Nd:YAG laser is poorly absorbed by haemoglobin or water but intensely absorbed by tissue protein. Thus, laser operates in Qswitching mode to store energy in the resonator during pumping action followed by release of a single, short pulse of high energy. The main advantage of laser is its thermal stability to produce high quality continuous beam at room temperature [23, 24].

\section{Uses of Nd:YAG laser}

Nd-YAG laser is the powerful laser used for coagulating action among all laser used for surgical action.

\subsubsection{Ruby Laser}

It is a solid-state laser emits red light with wavelength $694 \mathrm{~nm}$ or $0.6 \mu \mathrm{m}$. Ruby laser is excited by flash lamp and can be Q- switched for getting high quality pulsed laser beam. Blood vessels and transparent fluid does not absorb this radiation. It's a pulsed laser and capable of large field of energy. Initially, ruby laser used in ophthalmology. Currently used primarily to irradiate port-wine stain lesion of skin [24,25].

\subsection{Argon Plasma Coagulator}

Argon plasma coagulator (APC) is a device is used for thermal coagulation of tissue. APC is used in open and laproscopic surgery. This technique is non-contact and was adopted in 1991 for flexible endoscopy [26-28].

\subsubsection{Basic Principle of APC}

APC is electrocoagulation device. It uses high frequency Monopolar current to target tissue through ionized argon gas (argon plasma). Electrons flows through electrically activated ionized argon gas chamber and the probe extended to the targeted tissue. Current produce coagulation at the tissue surface. Depth of coagulation depends on the power of generator, flow rate of argon gas, duration of application and distance of probe from the targeted tissue [29]. A thin superficial and electrically insulating layer is developed with thermal coagulation [30]. This insulating layer increases electrical resistance in the treated area, which results current through another point of tissue having low resistance [3133]. With long duration of application, carbonization, vaporization and deep tissue injury may occur.

\subsubsection{Equipmental Part of APC}

APC consist of high frequency Monopolar electrosurgical generator, Argon gas source, flow meter, catheters, grounding pad, and foot switch for activation of gas and energy. Schematic diagram is shown in figure 12.

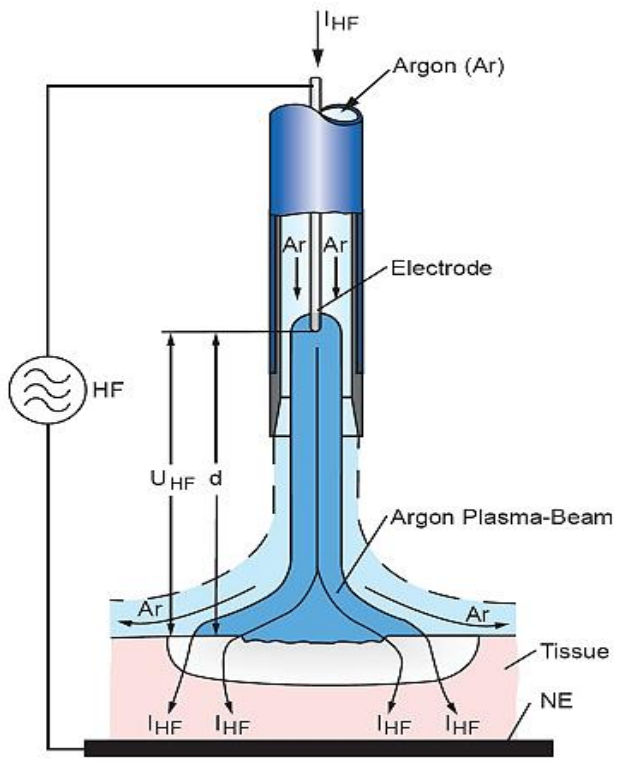

Figure 12: Schematic presentation of APC: Argon gas flows through chamber containing electrode wire. Discharge is ignite by the high frequency voltage $U_{H F}$ between the wire and tissue. After breakdown high frequency current $I_{H F}$ flows through tissue causing coagulation effect and NE is the neutral electrode [28] 
Available probes direct the argon plasma. These probes are available in the variety of diameters and length $2.3 \mathrm{~mm}$ with $440 \mathrm{~cm}$ length, and 3.2 $\mathrm{mm}$ with $220 \mathrm{~cm}$ length. Foot switch synchronize the flow of argon gas and delivery of electrical current. Power generator delivers the output voltage of 5000-6500 V and the power can be adjusted between 0 and $155 \mathrm{~W}$. Flow of argon gas is adjusted from $0.5 \mathrm{~L} / \mathrm{mm}$ to $7 \mathrm{~L} / \mathrm{mm}$ and the operative distance between the probe must be in the range from 2 to $8 \mathrm{~mm}$ [34].

\subsubsection{Technical Details}

Device setting is varies depending upon the study protocol. In general, for hemostasis of superficial vascular lesion low power and low gas flow rate is used with $40 \mathrm{~W}$ to $50 \mathrm{~W}$ and $0.8 \mathrm{~L} / \mathrm{mm}$. In this setting probe tip must be close to the tissue to allow argon gas plasma to contact with targeted tissue. Tissue surface must be cleaned and free from any liquid (including blood). If the tissue surface is not clear, coagulated surface layer beneath inadequately treat tissue. APC is perform for the duration of 0.5 to 2 second. For tissue ablation higher output setting is used up to $70 \mathrm{~W}$ to $90 \mathrm{~W}$ with $1 \mathrm{~L} / \mathrm{mm}$ gas flow rate. Very high flow rate may result gaseous distention and discomfort to the patient.

\section{Conclusions}

Present day surgery has become very safe and patient friendly, thanks to the advancement in new technology. We need to make judicious use of these energy devices in order to maximize the benefits and minimize the harm. This requires an in depth understanding of the physics underlying the working of these surgical implements. Monopolar electric diathermy with a low current setting of cutting with blend is appropriate for both cutting and dissecting most tissue. However, bipolar diathermy should be preferred while dissecting the tissue in brain or working near vital organ such as nerves, parathyroid glands and important vessels and intestine. Large vessels can be coagulated using vessels sealing devices. Such as ligasure/enseal/thunderbeat for vessels diameter up to $7 \mathrm{~mm}$. Lasers are most effective in the field of eye surgery, ear, nose and throat surgery as they offered precise narrow beam of light energy which can even passed through endoscopic instrument. Healing of tissue treated by laser is associated with minimal pain and minimal edema.

\section{Declarations}

\subsection{Acknowledgement}

One of the authors, Darakhshan Qaiser, would like to acknowledge University Grant Commission (UGC) for awarding Fellowship in the scheme Post-Doctoral Fellowship for Women.

\subsection{Competing Interests}

The authors declared that no conflict of interest exist in the publishing this article.

\section{How to Cite this Article:}

D. Qaiser, P. Ranjan, K. Kataria, A. Dhar, and A. Srivastava, "Physics for Surgeons - Part 4: Energy Devices in Surgery", Int. Ann. Sci., vol. 9, no. 1, pp. 122131, Apr. 2020. doi: 10.21467/ias.9.1.122-131

\section{Reference}

[1] Srivastava A, Sood A, Joy SP, and Woodcock J, "Principles of physics in surgery: the laws of flow dynamics physics for surgeons - Part 1," Indian J. Surg., 2009, vol. 71 (40), pp. 182-187.

[2] Srivastava A et al., "Principles of Physics in Surgery: The Laws of Mechanics and Vectors Physics for Surgeons-Part 2," Indian J. Surg., 2010, vol. 72(5), pp. 355-361.

[3] Qaiser D, Srivastava A, Ranjan P, and Kataria K, "Physics for Surgeons Part 3: Why Cyst Is Spherical in Shape?," Indian J. Surg., 2017, vol. 79(2), pp. 143-147.

[4] Obonna GC, Mishra RK, "Differences between Thunderbeat, Ligasure and Harmonic Scalpal Energy system in minimally Invasive Surgery”, World Journal of LapSurg. 2014, vol. 7(1), pp. 41-44.

[5] Munro MG, Fundamental of Electrosurgery Part I: Principles of radiofrequency energy for surgery. In : L S. Feldman, P. Fuchshuber, D B. Jones, editors. The Fundamental use of surgical energy (FUSE) Manual. New York: Springer; 2012, pp. 15-60.

[6] Geddes LA, Silva LF, Dewitt DP, Pearce JA, "What's New Electrosurgical instrumentation?", MedInstrum, 1977, vol. 11, pp. 355-361.

[7] Johan wisely SD, “ Philosopher of electricity”, Med Instrum, 1973, vol. 7,pp. 307.

[8] Power FH, Barnes AC, "Sterilization by means of peritoneoscopic fulguration: a preliminary report", Am. J. Obstet Gynecol.,1941, vol. 41,pp. 1038-1043.

[9] Frangenheim H, Culdoscopy Vs Laproscopy: The first book on Gynecological Endoscopy and Cold Light, Gregorz Litynski, JSLS , 1997, vol. 1, pp 357-361.

[10] Rioux JE, Bipolar electrosurgery: a short history, J. Minim Invasive Gynecol., 2007,vol.14, pp. 538-541.

[11] Ohm GS, Kette DG , Mathematisch bearbeitet 1827, 
D. Qaiser et al., Int. Ann. Sci.; Vol. 9, Issue 1, pp:122-131, 2020

Berlin, Bei T.H. Riemann.

[12] Zenker M, Argon plasma coagulation, GMS Krankenhaushygiene interdisziplinar, 2008, vol. 3(1), pp. 1-5.

[13] Bulsara KR, Shukla S, Nimjee SM, History of Bipolar Coagulation, Neurosurgical review, 2006, vol. 29(2), pp. 93-96.

[14] Kennedy JS, Stranahan PL, Taylor KD, Chandller JG, High burst-strength Feedback controlled bipolar vessel sealing, Surgicalendoscopy, Surg. Endosc. 1998, vol. 12(6), pp. 876-878.

[15] Macario A, Dexter F, Sypal J, Cosgriff N, Heniford TB, Operative Time and other outcomes of the Electrothermal Bopolar Vessel sealing system (LigaSure $^{\mathrm{TM}}$ ) Versus other Methods for Surgical Hemostasis: A Meta-analysis, Surgical Innovations, 2008, vol. 15(4), pp. 284-291.

[16] Smith R, Pasic R, The role of sealing technologies in laproscopic surgery, Surg. Technol.Int, 2008, vol. 17, pp. 208-212.

[17] Takada M, Ichihara T, Kuroda Y, Comparative study of electrothermal bipolar vessel sealing and ultrasonic coagulation shears in laparoscopic colectomy", Surg. Endosc. 2005, vol. 19(7), pp. 226-228.

[18] Milson J, TrenchevaK, Monette S, Pavoor R, Shukla P, Ma J, Sonoda T, Evaluation of safety, Efficacy and versatility of a new surgical energy device (thunderbeat) in comparison with harmonic ACE, Ligasure $\mathrm{V}$ in aporcine model", J. Laparoendosc Advanced Surg. Tech, 2012, vol. 4, pp. 378-386.

[19] Seehofer D, Mogl M, Knoop SB, Unger J, Schirmeier A, Chopra S, Enrich D, safety and efficacy of new integrated bipolar and ultrasonic scissors compared to conventional laparoscopic $5 \mathrm{~mm}$ sealing and cutting instrument, Surg. Endosc. 2012, vol. 26, pp. 2541-2549.

[20] Maiman T, Stimulated optical radiation in ruby lasers, Nature 1960, vol.187, pp. 493-494.

[21] Azadgoli B, Baker R.Y, Laser applications in surgery, Ann. Transl. Med. 2016, vol. 4(23), pp. 452.doi: 10.21037/atm.2016.11.

[22] Shokrollahi K, Raymond E, Murison MSC, Laser: Principles and Surgical Applications, J. Surg. 2004, Vol. 2(1), pp. 28-34.

[23] Kilmer SL, Lee MS, Grevelink JM, Flotte TJ, Anderson RR, The Q-switched Nd:YAG laser effectively treats tattoos. A Controlled dose response study, Arch Dermatol, 1993, vol. 129, pp. 971-978.

[24] Spicer MS, Goldberg DJ, Laser in Dermatology, J. Am. Acad. Dematol, 1996, vol. 34, pp. 1-25.

[25] Raulin C, "IPL technology: a review", Lasers Surg Med 2003, vol. 32, pp. 78-87.
[26] Yoneda KY, Colt H, Nicholas S, Stollenwerk, Lung Cancer Emergencies, IASLC Thoracic oncology (second ediction), 2018, pp. 590-607.

[27] Forlinsky KJ, Barkun AN, Non variceal Upper Gastrointestinal Bleeding, Clinical Gastrointestinal Endoscopy (third edition), 2019, pp. 153-170.

[28] Gensberg GG, Barkun AN, Bosco JJ, Burdick JS, Isenberg GA, Nakao NL, Petersen BT, Silverman WB, Slivka A, Kelsey PB, Technology status Evaluation report: The Argon Plasma Coagulation, American Society for Gastrointestinal endoscopy (SAGE), 2002, vol. 55(7), pp. 807-810.

[29] Watson JP, Bennett MK, Griffin SM, Mattewson K, The tissue effect of argon plasma coagulation on esophageal and gastric mucosa, Gasrointest Endosc, 2000, vol. 52, pp. 342-5.

[30] Farin G, Grund KE, Technology of argon plasma coagulation with particular regard to endoscopic applications, Endoscop Surg, 1994, vol. 2, pp. 71-77.

[31] Waye J, How I use the argon plasma coagulator, Clin Perspect Gastorenterol, 1999, pp. 249-252.

[32] Johanns W, Luis W, Janssen J, Kahl S, Greiner L, Argon Plasma Coagulation (APV) in gastroenterology: experimental and clinical experiences, Eur $\mathbf{J}$ Gastroenterol Heprol, 1997, pp. 581-587.

[33] Platt Rc, Argon plasma electrosurgical coagulation, Biomed Sci Instrum, 1997, vol. 34, pp. 332-337.

[34] Nakamura S, Mitsunaga A, Murata Y, Suzuki S, Hayashi $\mathrm{N}$, Endoscopic induction of mucosal fibrosis by argon plasma coagulation (APC) for esophageal varices: a perspective randomized trial of ligation plus APC vs. ligation alone, Endoscopy, 2001, vol. 33, pp. 210-215.

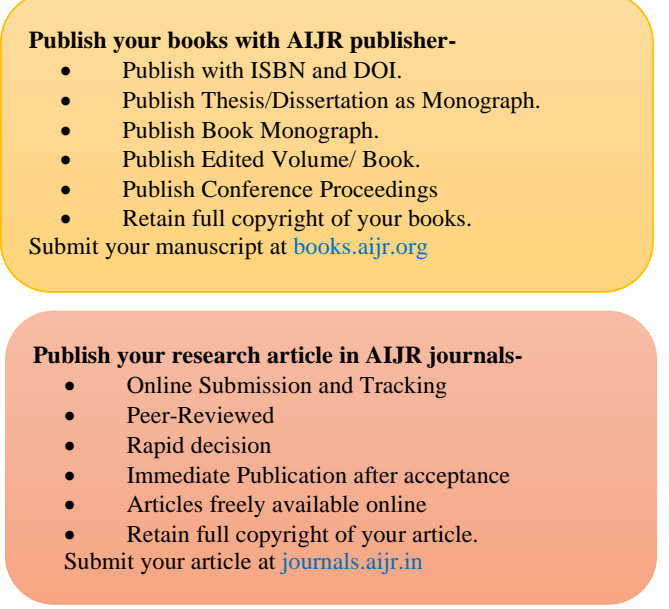

